\title{
Acellular pertussis vaccine given by accelerated schedule: response of preterm infants
}

\author{
M H Slack, D Schapira, R J Thwaites, C Schapira, J Bamber, M Burrage, J Southern, N Andrews, \\ E Miller
}

See end of article for authors' affiliations

.....................

Correspondence to: Dr Slack, Department of Paediatrics, St Mary's Hospital, Portsmouth P03 6AD, UK; marts@doctors.org.uk

Accepted 3 March 2003
Objective: To describe the immune response of preterm infants to a diphtheria/tetanus/three component acellular pertussis (DTaP) vaccine, under an accelerated schedule, and the effects of steroids on this response. To compare responses with those of term infants.

Design: Prospective observational study.

Setting: Five Wessex neonatal units; Hertfordshire immunisation clinics.

Patients: Infants born at $<32$ weeks; term controls.

Interventions: DTaP-Haemophilus influenzae type b vaccine given at 2, 3, and 4 months. Blood taken to assess antibody responses to vaccines.

Main outcome measures: lgG geometric mean concentrations (GMC) to vaccines.

Results: A total of 130 preterm (mean gestational age 29.1 weeks) and 54 term infants were recruited. After the third immunisation, preterm infants had similar GMCs to controls to diphtheria, tetanus, filamentous haemagglutinin (FHA), and pertactin (PRN), but a significantly lower GMC to pertussis toxin (PT). Responses to tetanus and PRN increased with age at the third immunisation, and those to tetanus, FHA, PRN, and PT increased with gestational age at birth. Response to tetanus correlated negatively with the number of doses of antenatal steroids received. There was no association between responses and postnatal steroids.

Conclusion: When immunised with a combined acellular pertussis- $H$ influenzae type b vaccine under an accelerated schedule, lgG GMC of preterm infants to PT was reduced. GMCs to tetanus, FHA, PRN, and PT increased with gestational age at birth, and GMCs to tetanus and PRN increased with age at the third immunisation. There is, however, no benefit in delaying immunisation. Anti-tetanus lgG decreased with increasing number of doses of antenatal steroids. There was no effect for postnatal steroids.
A cellular pertussis (aP) vaccines containing between one and five pertussis components are used in many countries for both primary and booster immunisations. Their acceptance is based on a reduced reactogenicity profile compared with whole cell pertussis (wP) vaccines and, for aP vaccines with three or more components, a similar level of protection against whooping cough. The degree of this efficacy depends, however, on the definition of disease used. ${ }^{1}$

The United Kingdom has been using both wP and aP vaccines in the primary immunisation schedule since 1999. Infants receive combined diphtheria/tetanus/pertussis (DTP), Haemophilus influenzae $b$ (Hib), and meningococcal serogroup C (MCC) vaccines under an accelerated schedule at 2, 3, and 4 months. It is recommended that preterm infants be immunised at the same chronological age as term infants. ${ }^{2}$

Previous studies have shown that preterm infants, when immunised with DTwP, produce adequate antibody responses to the vaccine antigens under differing schedules: 2,3 , and 4 months, ${ }^{3}$ or 2,4 , and 6 months, $^{45}$ or 3, 4, and 5 months, or 3, 4, and 10 months. ${ }^{6}$ However, there is little information on the response of preterm infants to DTaP vaccines, and none generated using the UK 2, 3, and 4 month schedule.

Preterm infants who develop chronic lung disease may be treated with steroids to reduce their need for ventilatory support; however, this practice is declining. The use of postnatal dexamethasone in the treatment of chronic lung disease has been suggested as one reason for the reduced immune response to Hib seen in some infants, ${ }^{7}$ although we found no evidence for an effect on either Hib or MCC responses. ${ }^{8}$ The effect of antenatal and postnatal steroids on the response of preterm infants to protein vaccines (DTP) has not, to our knowledge, been described previously.

This is the first study to describe the immune response of preterm infants to a three component DTaP vaccine given under the United Kingdom's accelerated schedule and to investigate the effects of steroids on their response.

\section{MATERIALS AND METHODS \\ Subjects}

Infants born at less than 32 completed weeks gestation were recruited from five neonatal units in one region of the United Kingdom: The Royal Hampshire County Hospital, Winchester; St Mary's Hospital, Portsmouth; Princess Anne Hospital, Southampton; North Hampshire Hospital, Basingstoke; Poole General Hospital, Poole. Results for Hib and MCC have been published elsewhere. ${ }^{8}$

Infants received their first immunisation as near to 2 months of age as clinically appropriate. Immunisation was delayed if the infant was still mechanically ventilated, clinically unstable, or if there were concerns about intercurrent sepsis. A control group of term infants attending clinics in Hertfordshire, England for routine immunisation were also recruited. Written informed consent was obtained

Abbreviations: aP, acellular pertussis; DTP, diphtheria/tetanus/ pertussis; FHA, filamentous haemagglutinin; GMC, geometric mean concentration; Hib, Haemophilus influenzae b; MCC, meningococcal serogroup C; PRN, pertactin; PT, pertussis toxin; wP, whole cell pertussis 
Table 1 Mean (range) age in days at first and third immunisation and number of days from third immunisation to blood taking for preterm and term infants

\begin{tabular}{|c|c|c|c|}
\hline & $\begin{array}{l}\text { Preterm } \\
(n=124)\end{array}$ & $\begin{array}{l}\text { Term } \\
(n=54)\end{array}$ & p Value* \\
\hline $\begin{array}{l}\text { Age at first immunisation } \\
\text { Age at third immunisation } \\
\text { Days from third } \\
\text { immunisation to blood } \\
\text { taking }\end{array}$ & $\begin{array}{l}66(51-116) \\
134(108-194) \\
32(23-51)\end{array}$ & $\begin{array}{l}60(41-84) \\
123(112-149) \\
33(21-63)\end{array}$ & $\begin{array}{l}<0.001 \\
<0.001 \\
0.745\end{array}$ \\
\hline
\end{tabular}

*Wilcoxon rank sum test.

from the infants' parents before enrolment, and ethical approval was obtained from the North Hertfordshire research ethics committee and the four local research ethics committees serving the five neonatal centres.

\section{Immunisations}

Both term and preterm infants received combined DTaP-Hib (Infanrix-Hib; GlaxoSmithKline, Rixensart, Belgium; $0.5 \mathrm{ml}$ dose containing $30 \mathrm{IU}$ diphtheria toxoid, $40 \mathrm{IU}$ tetanus toxoid, $25 \mu \mathrm{g}$ pertussis toxin (PT), $25 \mu \mathrm{g}$ filamentous haemagglutinin (FHA), $8 \mu \mathrm{g}$ pertactin (PRN), and $10 \mu \mathrm{g}$ purified capsular polysaccharide of Hib covalently bound to about $30 \mu \mathrm{g}$ tetanus toxoid) into the right thigh and MCC (Meningitec; Wyeth, Maidenhead, Berks, UK; $0.5 \mathrm{ml}$ dose containing $10 \mu \mathrm{g}$ meningococcal serogroup $\mathrm{C}$ oligosaccharide conjugated to about $15 \mu \mathrm{g} \mathrm{CRM}_{197}$ protein) into the left.

\section{Assays}

Blood was taken from the preterm infants by venepuncture into Microtainer Serum Separator tubes just before the first vaccination and 4-6 weeks after the third vaccination. Term infants had blood taken after the third immunisation only. Vaccine antibody titres were analysed by the Centre for Applied Microbiology and Research (CAMR), Salisbury, Wiltshire, UK by enzyme linked immunosorbent assay (ELISA).

\section{Statistical analysis}

Age at vaccination and gap from third dose to date of blood sample were compared with those in term infants using the Wilcoxon rank sum test; geometric means after third dose were compared using $t$ tests. Single variable linear regression analysis was performed to evaluate the influence of preimmunisation IgG concentrations, gestational age at birth, birth weight, age at third immunisation, number of doses of antenatal steroids, and number of courses of postnatal steroids on the IgG response to each of the vaccine antigens. The influence of variables with $\mathrm{p}<0.2$ in the single variable analysis was examined further using multivariable regression.

\section{RESULTS}

A total of 130 infants born at less than 32 completed weeks gestation were recruited to the study; 128 completed their primary immunisations (77 boys, 60\%). Two infants died before their third immunisation, the cause of death being unconnected with vaccination. No other infants were lost to follow up. After Hib and MCC analysis, ${ }^{8}$ insufficient blood was available to perform DTP serology on three infants, and in a further nine infants serology was incomplete. One infant who did not complete primary immunisations until 232 days was excluded from the final analysis. Fifty four term infants ( 34 boys, 63\%) were recruited to the control group. The mean gestational age at birth of the preterm infants was 29.1 weeks (range 24.3-31.7), and mean weight at birth and first immunisation was $1270 \mathrm{~g}$ (range 490-2114) and $2594 \mathrm{~g}$ (range 1470-4020) respectively. Table 1 shows the mean age in days at the first and third immunisation and the mean number of days from third immunisation to date of blood sample for the preterm infants and controls.

First immunisation was delayed beyond 70 days of age in 20 infants $(16 \%)$ for one or more of the reasons stated above. No infant in either the preterm or term group experienced adverse events after immunisation that served as contraindications to subsequent immunisation.

Table 2 shows the pre-immunisation IgG geometric mean concentrations (GMCs) to the vaccine antigens in the preterm infants.

All showed strong positive correlations with increasing gestational age at birth. Table 3 shows IgG GMCs one month after completion of the primary schedule for preterm and term infants. Compared with term infants, preterm infants had similar responses to diphtheria toxoid, tetanus toxoid, FHA, and PRN, but a significantly decreased response to PT. The proportion of preterm infants achieving $\mathrm{a} \geqslant 4$-fold rise in diphtheria toxoid, tetanus toxoid, FHA, PRN, and PT titres was $99 \%, 57 \%, 91 \%, 93 \%$, and $83 \%$ respectively. Fourfold rises were not calculated for term infants, as no pre-immunisation blood was taken.

Table 4 shows single variable linear regression analysis of the influence of a number of variables on the final IgG GMC against each vaccine.

Each variable gave a p value of $<0.2$ for at least one of the IgG responses and so all were included in the multivariable model. Table 5 shows the results of the multivariable analysis.

\section{Influence of age on post-immunisation responses}

In the multivariable model, IgG concentrations in response to tetanus toxoid, FHA, PRN, and PT correlated positively with gestational age at birth. In addition, IgG concentrations in response to tetanus toxoid and PRN correlated positively with age at third immunisation.

Table 2 Pre-immunisation lgG geometric mean concentrations to vaccine antigens for preterm infants and their association with gestational age at birth

\begin{tabular}{llll}
\hline Antibody & IgG GMC & $\begin{array}{l}\text { Percentage increase per week of } \\
\text { gestational age at birth }\end{array}$ & p Value \\
\hline Diphtheria & $0.015(0.013$ to 0.019$)$ & $7.5(3.4$ to 1.5$)$ & $<0.001$ \\
Tetanus & $0.17(0.14$ to 0.22$)$ & $11.5(7.4$ to 15.7$)$ & $<0.001$ \\
FHA & $2.35(1.99$ to 2.77$)$ & $8.1(4.7$ to 11.3$)$ & $<0.001$ \\
PRN & $1.75(1.44$ to 2.12$)$ & $5.9(2.0$ to 9.8$)$ & 0.004 \\
PT & $1.51(1.25$ to 1.83$)$ & $9.7(6.1$ to 13.4$)$ & $<0.001$ \\
\hline
\end{tabular}

Values in parentheses are $95 \%$ confidence intervals.

GMC, Geometric concentration; FHA, filamentous haemagglutinin; PRN, pertactin; PT, pertussis toxin. 
Table $3 \mathrm{lg}$ geometric mean concentrations in response to vaccine antigens for preterm and term infants one month after third dose of vaccines

\begin{tabular}{llll}
\hline Antibody & Preterm & Term & p Value* \\
\hline Diphtheria & $1.50(1.33$ to 1.68$) n=120$ & $1.75(1.36$ to 2.26$) n=46$ & 0.20 \\
Tetanus & $1.09(0.94$ to 1.26$) n=121$ & $1.30(1.03$ to 1.63$) n=47$ & 0.20 \\
FHA & $54.7(48.2$ to 62.1$) n=119$ & $59.8(48.7$ to 73.4$) n=47$ & 0.46 \\
PRN & $82.6(70.1$ to 97.3$) n=122$ & $86.6(64.9$ to 115.4$) n=49$ & 0.77 \\
PT & $21.0(18.4$ to 23.9$) n=122$ & $33.4(28.2$ to 39.5$) n=50$ & $<0.001$ \\
\hline
\end{tabular}

Values in parentheses are $95 \%$ confidence intervals.

* $t$ Test.

FHA, filamentous haemagglutinin; PRN, pertactin; PT, pertussis toxin.

\section{Influence of pre-immunisation IgG concentrations}

The final IgG concentrations in response to tetanus toxoid, FHA, and PRN in preterm infants correlated negatively with pre-immunisation levels. For PT the negative association did not reach significance, and for diphtheria toxoid there was no evidence of an association.

\section{Influence of birth weight}

IgG responses to tetanus toxoid and PT correlated negatively with birth weight. We found no evidence for an association between responses to diphtheria toxoid, FHA, and PRN and weight at birth.

\section{Steroid use}

Of the 124 infants for whom responses to DTP are available, $101(81 \%)$ received antenatal steroids. Antenatal steroid status of a further four infants was unknown. There was no association between maternal antenatal steroid status and response to diphtheria toxoid, FHA, PRN, or PT. However, response to tetanus toxoid correlated negatively with the number of doses of antenatal steroids received by the infants' mothers (anti-(tetanus toxoid) IgG GMCs for $0,1,2,3$, and 4 doses of antenatal steroids were 1.75, 1.02, 1.06, 1.01, and $0.83 \mathrm{IU} / \mathrm{ml}$ respectively; $\mathrm{p}=0.017)$. Fifteen infants $(12 \%)$ received postnatal dexamethasone for chronic lung disease.

Table 4 Single variable linear regression analysis of influence of gestational age, birth weight, pre-immunisation lgG levels, age at completion of immunisations, and use of antenatal and postnatal steroids on $\lg G$ response of preterm infants to vaccine antigens

\begin{tabular}{|c|c|c|c|c|c|c|}
\hline & \multicolumn{6}{|c|}{ Percentage change in IgG titre per unit change in variable } \\
\hline & $\begin{array}{l}\text { Gestational age } \\
\text { (weeks) }\end{array}$ & $\begin{array}{l}\text { Birth weight } \\
(100 \mathrm{~g})\end{array}$ & $\begin{array}{l}\text { Pre-immunisation } \\
\text { lgG level (IU/ml) }\end{array}$ & $\begin{array}{l}\text { Age at } \\
\text { completion } \\
\text { (weeks) }\end{array}$ & $\begin{array}{l}\text { Antenatal } \\
\text { steroids } \\
\text { (number of } \\
\text { doses) }\end{array}$ & $\begin{array}{l}\text { Postnatal } \\
\text { steroids } \\
\text { (number of } \\
\text { courses) }\end{array}$ \\
\hline $\begin{array}{l}\text { Diphtheria } \\
\text { Tetanus } \\
\text { FHA } \\
\text { PRN } \\
\text { PT }\end{array}$ & $\begin{array}{l}+1.6 \dagger^{*} \\
-1.3 \\
-0.7 \\
+0.07 \\
+1.2\end{array}$ & $\begin{array}{l}+1.0 \dagger \\
-0.92 \\
-0.70 \\
-0.43 \\
-0.51\end{array}$ & $\begin{array}{l}+0.68 \\
-15 \dagger \dagger \\
-13 \dagger \\
-27 \dagger \dagger \dagger \\
-2.9\end{array}$ & $\begin{array}{l}+0.82 \\
+4.7 \dagger \dagger \dagger \\
+2.4 \dagger \dagger \\
+3.4 \dagger \dagger \\
-0.05\end{array}$ & $\begin{array}{l}-3.2 \\
-6.2 \dagger \\
-2.1 \\
-2.6 \\
-3.1\end{array}$ & $\begin{array}{l}-1.0 \\
+4.0 \\
+12.6 \dagger \dagger \\
-2.9 \\
-4.9\end{array}$ \\
\hline
\end{tabular}

*Example: $1.6 \%$ increase in diphtheria lgG for each week of gestational age at birth $\mathrm{tp}<0.2 ;+\uparrow \mathrm{p}<0.05 ;+\dagger+\mathrm{p}<0.01$.

FHA, filamentous haemagglutinin; PRN, pertactin; PT, pertussis toxin.

Table 5 Multivariable analysis of influence of gestational age, birth weight, pre-immunisation lgG levels, age at completion of immunisations, and use of antenatal and postnatal steroids on lgG response of preterm infants to vaccine antigens

\begin{tabular}{|c|c|c|c|c|c|c|}
\hline & \multicolumn{6}{|c|}{ Percentage change in lgG titre per unit change in variable $p$ value } \\
\hline & $\begin{array}{l}\text { Gestational age } \\
\text { (weeks) }\end{array}$ & Birth weight $(100 \mathrm{~g})$ & $\begin{array}{l}\text { Pre-immunisation IgG } \\
\text { level (IU/ml) }\end{array}$ & $\begin{array}{l}\text { Age at completion } \\
\text { (weeks) }\end{array}$ & $\begin{array}{l}\text { Antenatal steroids } \\
\text { (number of doses) }\end{array}$ & $\begin{array}{l}\text { Postnatal steroids } \\
\text { (number of courses) }\end{array}$ \\
\hline Diphtheria & $\begin{array}{l}+2.2^{*} \\
(-2.5 \text { to }+7.0) \\
p=0.36\end{array}$ & $\begin{array}{l}+0.7 \\
(-1.8 \text { to }+3.1) \\
p=0.58\end{array}$ & $\begin{array}{l}-4.5 \\
(-16.0 \text { to }+7.0) \\
p=0.44\end{array}$ & $\begin{array}{l}+1.1 \\
(-1.7 \text { to }+4.0) \\
p=0.42\end{array}$ & $\begin{array}{l}-1.8 \\
(-8.3 \text { to }+4.8) \\
p=0.59\end{array}$ & $\begin{array}{l}+4.8 \\
(-11.2 \text { to }+20.8) \\
p=0.55\end{array}$ \\
\hline Tetanus & $\begin{array}{l}+7.1 \\
(+1.5 \text { to }+12.7) \\
p=0.014\end{array}$ & $\begin{array}{l}-2.8 \\
(-5.6 \text { to }+0.04) \\
p=0.053\end{array}$ & $\begin{array}{l}-18.3 \\
(-31.6 \text { to }-5.0) \\
p=0.007\end{array}$ & $\begin{array}{l}+5.3 \\
(+2.2 \text { to }+12.2) \\
p=0.001\end{array}$ & $\begin{array}{l}-9.2 \\
(-16.8 \text { to }-1.7) \\
p=0.017\end{array}$ & $\begin{array}{l}-2.6 \\
(-21.2 \text { to }+16.0) \\
p=0.79\end{array}$ \\
\hline FHA & $\begin{array}{l}+5.9 \\
(+0.9 \text { to }+10.9) \\
p=0.02\end{array}$ & $\begin{array}{l}-2.0 \\
(-4.5 \text { to }+0.49) \\
p=0.12\end{array}$ & $\begin{array}{l}-17.0 \\
(-32.8 \text { to }-1.2) \\
p=0.035\end{array}$ & $\begin{array}{l}+2.2 \\
(-0.7 \text { to }+5.0) \\
p=0.14\end{array}$ & $\begin{array}{l}-5.7 \\
(-12.6 \text { to }+1.1) \\
p=0.097\end{array}$ & $\begin{array}{l}+10.6 \\
(-4.2 \text { to }+25.5) \\
p=0.16\end{array}$ \\
\hline PRN & $\begin{array}{l}+7.4 \\
(+1.5 \text { to }+13.3) \\
p=0.015\end{array}$ & $\begin{array}{l}-0.7 \\
(-3.7 \text { to }+2.2) \\
p=0.62\end{array}$ & $\begin{array}{l}-36.4 \\
(-51.7 \text { to }-21.1) \\
p<0.001\end{array}$ & $\begin{array}{l}+5.6 \\
(+2.1 \text { to }+9.1) \\
p=0.002\end{array}$ & $\begin{array}{l}-3.0 \\
(-11.3 \text { to }+5.3) \\
p=0.476\end{array}$ & $\begin{array}{l}-4.1 \\
(-22.0 \text { to }+13.8) \\
p=0.65\end{array}$ \\
\hline PT & $\begin{array}{l}+10.6 \\
(+5.2 \text { to } 15.9) \\
p<0.001\end{array}$ & $\begin{array}{l}-3.4 \\
(-5.9 \text { to }-0.9) \\
p=0.008\end{array}$ & $\begin{array}{l}-11.3 \\
(-25.5 \text { to }+3.0) \\
p=0.12\end{array}$ & $\begin{array}{l}+0.9 \\
(-2.1 \text { to }+3.9) \\
p=0.56\end{array}$ & $\begin{array}{l}-6.8 \\
(-14.0 \text { to }+0.3) \\
p=0.061\end{array}$ & $\begin{array}{l}+11.2 \\
(-4.2 \text { to }+26.6) \\
p=0.15\end{array}$ \\
\hline
\end{tabular}

Values in parentheses are $95 \%$ confidence intervals.

*Example: $2.2 \%$ increase in diphtheria lgG for each week of gestational age at birth.

FHA, filamentous haemagglutinin; PRN, pertactin; PT, pertussis toxin. 
No infant was still receiving steroids at the time of immunisation. There was no association between the use of postnatal steroids and response to diphtheria toxoid, tetanus toxoid, FHA, PRN, or PT. However, because of the low number of infants receiving postnatal steroids, their effect could not be estimated with high precision, as shown by the wide confidence intervals.

\section{DISCUSSION}

We are the first to describe the response of preterm infants to a combined DTaP-Hib vaccine given under an accelerated schedule. In addition, the preterm infants in this study were of a lower mean gestational age at birth than in the two previously reported studies ${ }^{910}$ investigating the response of preterm infants to acellular vaccines under non-accelerated schedules.

Schloesser et al ${ }^{9}$ showed that preterm infants (mean gestational age 30.8 weeks) immunised with a two component aP vaccine containing PT and FHA given at 2, 4, and 6 months had a reduced GMC for both PT and FHA compared with term infants, although the proportion of infants achieving a greater than fourfold rise in antibody concentration was high. A second study ${ }^{10}$ investigating the response to a combined three component DTaP-hepatitis $\mathrm{B}$ vaccine, containing PT, FHA, and PRN given at 3, 5, and 11 months, found that preterm infants (mean gestational age 32 weeks) had a similar response to tetanus toxoid, PT, and FHA to term infants, but a significantly reduced response to diphtheria toxoid and PRN.

We have shown that, compared with term infants, responses to diphtheria toxoid, tetanus toxoid, FHA, and PRN antigens are similar, whereas that to PT is decreased when a three component aP vaccine is given under an accelerated schedule. Except for the tetanus toxoid response, the proportion of preterm infants achieving $a \geqslant 4$-fold rise in IgG titre in response to the vaccine antigens was high.

Maternally derived IgG crosses the placenta in the last trimester of pregnancy. It is therefore not surprising that pre-immunisation IgG concentrations to vaccine antigens increased with increasing gestational age at birth. However, we have also shown that IgG concentrations in response to tetanus toxoid, FHA, and PRN after immunisation correlated negatively with those before. This may be explained by higher concentrations of pre-existing antibody interfering with the immune response to the vaccine antigens. The negative correlation we found between birth weight and IgG responses to tetanus toxoid, FHA, and PT is interesting. That to FHA is explained by increased maternal IgG in the more mature, larger babies. However, that to tetanus toxoid and PT persists when controlled for pre-immunisation IgG concentrations. The actual effect on IgG responses was small, and the clinical significance questionable.

After adjustment for the influence of pre-existing maternal antibody, IgG responses to tetanus toxoid, FHA, PRN, and PT showed strong positive correlations with gestational age at birth, and the responses to tetanus toxoid and PRN showed strong correlations with age at the third immunisation. These findings suggest greater immunological maturity with increasing gestational age, although the improved response seen with age at the third immunisation may also be due to postnatal decreases in maternal IgG. These findings are of particular interest with reference to the pertussis antigens. Preterm infants are especially susceptible to serious pertussis infection, and timely immunisation is therefore desirable.
Early protection against pertussis forms the basis of the accelerated schedule used in the United Kingdom. Although we have shown increasing IgG responses to PRN when immunisation was delayed, this must be offset by the fact that the IgG GMC to PRN in the preterm infants was comparable to that seen in the term infants. There is therefore no benefit to be gained by delaying immunisation in these infants.

We have shown a reduction in tetanus toxoid IgG response with increasing doses of antenatal steroids given to the preterm infants' mothers. We found a similar, though less significant, trend for anti-Hib IgG. ${ }^{8}$ This reduction in immune response to tetanus toxoid is, of course, greatly outweighed by the benefit that the use of antenatal steroids has brought to the preterm infant in lung maturation before preterm delivery. However, it does raise the question as to whether multiple doses of antenatal steroids have an impact on the immune responsiveness of the infant for weeks after the steroids are given.

In summary, we have shown that the IgG response of preterm infants to pertussis toxin is reduced, whereas that to diphtheria toxoid, tetanus toxoid, FHA, and PRN antigens is similar to that of term infants when given in a combined acellular pertussis-Hib vaccine under an accelerated schedule.

\section{Authors' affiliations}

M H Slack, R J Thwaites, Department of Paediatrics, St Mary's Hospital, Portsmouth, UK

D Schapira, C Schapira, Department of Paediatrics, Royal Hampshire County Hospital, Winchester, UK

J Bamber, Department of Neonatal Medicine, Princess Anne Hospital, Southampton, UK

M Burrage, Centre for Applied Microbiology and Research, Salisbury, Wiltshire, UK

J Southern, N Andrews, E Miller, Immunisation Division, Communicable Disease Surveillance Centre, Public Health Laboratory Service, London, UK

Financial support: Department of Health; Meningitis Research Foundation.

\section{REFERENCES}

1 Olin P, Rasmussen F, Gustafsson L, et al. Randomised controlled trial of twocomponent, three-component, and five-component acellular pertussis vaccines compared with whole cell pertussis vaccine. Lancet 1997;350:1569-77.

2 Department of Health. Immunisation against infectious diseases, 1996. London: HMSO, 1996.

3 Ramsay ME, Miller E, Ashworth LAE, et al. Adverse events and antibody response to accelerated immunisation in term and preterm infants. Arch Dis Child 1995;72:230-2.

4 D'Angio CT, Maniscalco WM, Pichichero ME. Immunologic response of extremely preterm infants to tetanus, Haemophilus influenzae and polio immunizations. Pediatrics 1995;96:18-22.

5 Bernbaum JC, Daft A, Anolik R, et al. Response of preterm infants to diphtheria-tetanus-pertussis immunizations. J Pediatr 1985;107:184-8.

6 Conway S, James J, Balfour A, et al. Immunisation of the preterm baby. J Infect 1993;27:143-50.

7 Robinson MJ, Campbell F, Powell P, et al. Antibody response to accelerated Hib immunisation in preterm infants receiving dexamethasone for chronic lung disease. Arch Dis Child Fetal Neonatal Ed 1999:80:F69-71.

8 Slack MH, Schapira D, Thwaites RJ, et al. Immune response of preterm infants to meningococcal serogroup $C$ and combined diphtheria-tetanus toxoidsacellular pertussis-Haemophilus influenzae type b conjugate vaccines. J Infect Dis 2001;184:1617-20.

9 Schloesser RL, Fischer D, Otto W, et al. Safety and immunogenicity of an acellular pertussis vaccine in preterm infants. Pediatrics 1999; 103:e60

10 Faldella G, Alessandroni R, Magini GM, et al. The preterm infant's antibody response to a combined diphtheria, tetanus, acellular pertussis and hepatitis $B$ vaccine. Vaccine 1998;16:1646-9. 